\title{
REMOVAL OF Pb(II) FROM AQUEOUS SOLUTION BY SORPTION ON USED TEA LEAVES
}

\author{
TAJMERI S. A. ISLAM, HOSNE ARA BEGUM, MOHAMMAD ABUL HOSSAIN AND \\ MOHAMMAD TANVIR RAHMAN \\ Department of Chemistry, University of Dhaka, Dhaka-1000, Bangladesh
}

(Received revised copy: August 20, 2009)

\begin{abstract}
Batch sorption study was performed using used black tea leaves (UBTL) as a low-cost adsorbent for the removal of lead (II) from aqueous solutions. Experiments were conducted as a function of contact time, initial metal ion concentration, solution $\mathrm{pH}$ and temperature. The sorption of $\mathrm{Pb}$ (II) on used tea leaves increases with increase of initial $\mathrm{pH}$ of solution upto a certain limit which corresponds to the $\mathrm{pH}$ nearly 5 . The sorption isotherms follow Langmuir equation better than Freundlich equation. Again the Langmuir equation is more applicable at higher temperatures compared to those at low temperature at all $\mathrm{pH}$. The monolayer sorption capacity decreases with increase in processing temperature but the overall sorbed amount increased with the increase in temperature at all $\mathrm{pH}$. The positive value of estimated heat of sorption suggests the activated sorption. A probable mechanism of the sorption of $\mathrm{Pb}(\mathrm{II})$ on used tea leaves was proposed based on the surface charge of used tea leaves and the change of charge of $\mathrm{Pb}(\mathrm{II})$ with the $\mathrm{pH}$ of solution.
\end{abstract}

\section{INTRODUCTION}

Lead (II) is one of the highly toxic metal ions to the aquatic lives and human beings even at very low concentration. According to $\mathrm{WHO}$, the permissible limit of $\mathrm{Pb}$ (II) in drinking water is $0.005 \mathrm{mg} / \mathrm{L}$. All the compounds containing lead are considered as cumulative poisons that affect the gastrointestinal track, nervous system and sometimes both of biological system ${ }^{(1)}$. The chief sources of lead in water are the effluents of processing industries. Lead can enter the body through inhalation, and dermal contact with lead compounds. Upon reaching the blood stream, lead affect blood cells and the central nervous system. Lead poisoning causes damage to liver, kidney and reduction in hemoglobin formation, mental retardation, infertility and abnormalities in pregnant women. Fetuses and children under the age of seven and are most susceptible to lead poisoning, which has long-term and irreversible effects ${ }^{(2)}$. The symptoms of lead poisoning include headaches, poor appetite, trouble in sleeping, crankiness and vomiting.

Since the lead salts are widely used in industries; factories of batteries, paints, varnishes, solderings etc., the improper disposal of the wastes from these industries causes lead pollution in the environment. Various methods are currently used for removal of lead and other heavy metals from aquatic media including precipitation ${ }^{(3)}$, coagulation $^{(4)}$, filtration ${ }^{(5)}$, flotation ${ }^{(6,7)}$, sedimentation ${ }^{(7)}$, membrane process and electrochemical technique ${ }^{(8)}$, ion-exchange ${ }^{(9)}$ and adsorption ${ }^{(10-14)}$ on solid. Many of these 
methods require high capital and recurring expenditure; consequently they are not suitable for small-scale industries. At low concentration removal is more efficient by ionexchange or adsorption on solid adsorbent. High capital and regeneration cost of activated carbon and ion-exchange resins have resulted in an increased search for low cost absorbent. In recent years, considerable attention has been devoted to the study of economical removal of $\mathrm{Pb}$ (II) from solution by sorption using agricultural materials such as rice husk ${ }^{(15)}$, sugar beat pulp ${ }^{(10)}$, clay soil $^{(11)}$, alfalfa biomass ${ }^{(12)}$, lignite carbon ${ }^{(13)}$, peat carbon $^{(14)}$ etc. Each method has merits and limitations in application. The present investigations revealed that the fresh and used tea leaves can be used as potential scavengers of heavy metal ions mainly $\mathrm{Cr}(\mathrm{VI})^{(16-17)}$ and $\mathrm{Cr}(\mathrm{III})^{(18)}$. The present research has been carried out to investigate the capability of used tea leaves to remove $\mathrm{Pb}$ (II) from aqueous solution at different temperatures and varied $\mathrm{pH}$. Thermodynamic parameters of sorption and its mechanism were also investigated.

\section{EXPERIMENTAL}

Preparation of Sorbent: Used black tea leaves (UBTLs) were prepared from Lipton TAAZA black tea leaves (Batch-03A, Manufacturing date: August 03, 2006). About 200 $\mathrm{g}$ of Lipton TAAZA tea leaves were added to about $700 \mathrm{~mL}$ of boiling distilled water. After 2 hours boiling of fresh tea leaves, leaves were washed with hot distilled water followed by cold distilled water for several times until the tea colour completely disappeared. After washing the tea leaves were initially dried at room temperature and eventually in an oven at $106{ }^{\circ} \mathrm{C}$ for 10 hours. Dried leaves were sieved through the metallic sieve of mesh size $0.25 \mathrm{~mm}$ and $0.30 \mathrm{~mm}$. The resultant leaves in the range of $0.25-0.30 \mathrm{~mm}$ size were stored in an air-tight bottle for sorption experiments.

Analysis of $\mathrm{Pb}(\mathrm{II})$ Solution: $1000 \mathrm{mg} / \mathrm{L}$ stock solution was prepared by dissolving required amount of $\mathrm{Pb}\left(\mathrm{NO}_{3}\right)_{2}$ salt (A.G Merck, Germany) in double distilled water in a Teflon volumetric flask. Different concentration of $\mathrm{Pb}(\mathrm{II})$ solutions were prepared by required dilution of stock solution. Concentration of $\mathrm{Pb}(\mathrm{II})$ in solutions before and after of sorption were analyzed by Atomic Absorption Spectrophotometer (AAS) (PerkinElmer A.A analyst 800) using air acetylene flame and Hollow cathode lamp. The absorbance was measured at the most sensitive wavelength of $283.3 \mathrm{~nm}$.

Determination of Optimum $\mathrm{pH}$ for Sorption Study: For the determination of optimum $\mathrm{pH}, 0.1 \mathrm{~g}$ of used tea leaves was taken in each of the ten bottles. $25 \mathrm{~mL}$ lead solution was taken in each bottle. The bottles were placed in a thermostatic mechanical shaker (SW B20, Fions Ltd. Germany), maintained at $30^{\circ} \mathrm{C}$ and were shaken continuously for five hours. The reagent bottles were successively withdrawn after shaking for definite time and the solutions were centrifuged. After centrifuge the $\mathrm{pHs}$ of the solutions were measured. The difference of $\mathrm{pH}$ from the initial values was estimated as $\Delta \mathrm{pH}$. A plot of initial $\mathrm{pH} v s \mathrm{pH}$, produces a curve which intersects the $\mathrm{X}$-axis at a point as shown in Fig. 1. 
Determination of Equilibrium Time: To determine the equilibrium time, $0.1 \mathrm{~g}$ of used tea leaves was taken in $25 \mathrm{~mL}$ of $100 \mathrm{mg} / \mathrm{L} \mathrm{Pb}$ (II) solution in each of a series of adsorption bottles. Before adsorption, $\mathrm{pH}$ of each bottle was maintained at $\mathrm{pH} 5.0$ because this is the $\mathrm{pH}$ of $100 \mathrm{mg} / \mathrm{L} \mathrm{Pb}$ (II) solution in double distilled water. The constant $\mathrm{pH}$ was obtained by drop-wise addition of $0.1 \mathrm{M} \mathrm{HNO}_{3}$ or $0.1 \mathrm{M} \mathrm{NaOH}$ solutions whichever was necessary. The final $\mathrm{pH}$ of each solution was checked after sorption, which showed that the $\mathrm{pH}$ of the solution did not change by more than 0.2 units. All the bottles were shaken in a thermostated mechanical shaker. The bottles were taken out from the shaker after different time intervals. The solution from the sorption bottle was centrifuged and analyzed. The experiment was performed at $30^{\circ} \mathrm{C}$. The amount sorbed vs sorption time plot is shown in Fig. 2.

Sorption Isotherms at Different Temperatures and $\mathrm{pH}$ : For the determination of sorption isotherm at $30^{\circ} \mathrm{C}$ and $\mathrm{pH} 4.0,25 \mathrm{~mL}$ solution of various concentrations of $\mathrm{Pb}$ (II) ranging from 20 to $80 \mathrm{mg} / \mathrm{L}$ were taken in 7 bottles containing each of $0.1 \mathrm{~g}$ used tea leaves and were shaken for 180 minutes, which was the equilibrium time as determined in previous section. After sorption for 180 minutes, the solution of each bottle was centrifuged and analyzed by AAS. Similar experiments were performed at 40 and $50{ }^{\circ} \mathrm{C}$ to obtain sorption isotherms at different temperatures and isotherms are shown in Fig. 3. Again, the experiments were repeated at $\mathrm{pH} 5.0$ and 6.0 using temperatures of 30,40 and $50{ }^{\circ} \mathrm{C}$. The results are presented in Figs. 4 and 5, respectively.

\section{RESULTS AND DISCUSSION}

Determination of Optimum $\mathrm{pH}$ for Sorption Study

Before measuring the equilibrium time for the adsorption of $\mathrm{Pb}(\mathrm{II})$ on UBTLs it was important to determine the optimum $\mathrm{pH}$ of the solution to be used for sorption experiments. Fig. 1 shows the optimum $\mathrm{pH}$ is 5.3 at which minimum variation of solution $\mathrm{pH}$ during sorption process was observed. Optimization of solution $\mathrm{pH}$ is very important

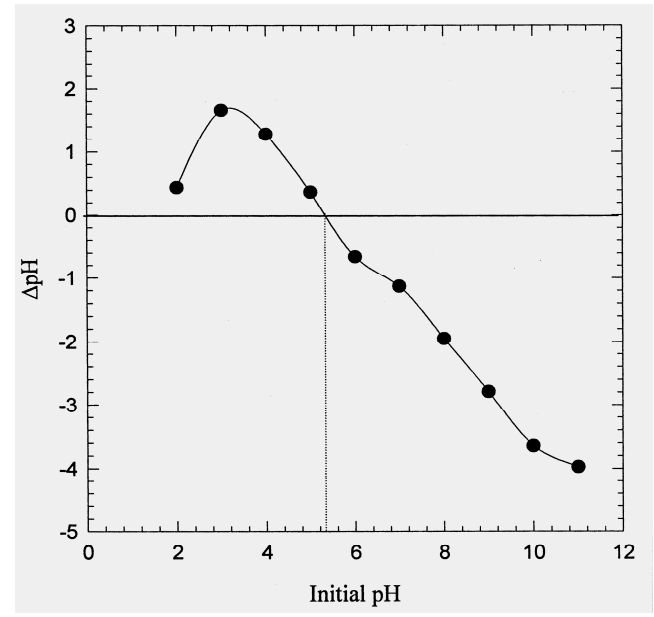

Fig. 1. Optimization of $\mathrm{pH}$ for the adsorption of lead (II) on UBTLs. 
because if the solution $\mathrm{pH}$ is changed with sorption time it will be difficult to identify the sorption $\mathrm{pH}$ as well as the amount sorbed. During the determination of the effect of $\mathrm{pH}$ on sorption of lead on UBTLs, $\mathrm{pH}$ of solutions were varied from 4 to 6 where the initial $\mathrm{pH}$ of solutions did not change significantly after sorption.

\section{Determination of Equilibrium Time}

Equilibrium time is essential for sorption study to construct the sorption isotherm. Equilibrium time is a stage where sorption reached the saturation stage. Under the present experimental conditions, the equilibrium time for the sorption of $\mathrm{Pb}$ (II) on UBTLs was found to be 2 hours. Figure 2 shows that the change of sorbate concentration is negligible at equilibrium time, and it was also observed that the removal of $\mathrm{Pb}$ (II) on UBTLs is nearly $94.5 \%$.

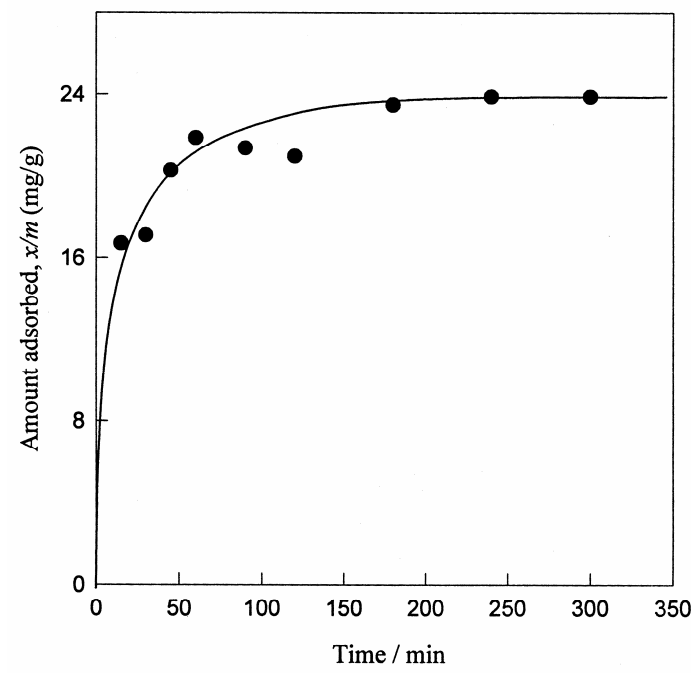

Fig. 2. Estimation of equilibrium time for the adsorption of lead (II) on UBTLs using pH 5.0 at 30.0 $\pm 0.5^{\circ} \mathrm{C}$

\section{Sorption Isotherm}

Sorption isotherm is an important parameter for the characterization of an sorption process. In this study, sorption isotherms were determined at three different temperatures using solutions of three different $\mathrm{pH}$ values. Under all the experimental conditions the amount sorbed increases with the increase of equilibrium concentration. The sorption isotherms were obtained by plotting equilibrium concentration $\left(C_{\mathrm{e}}\right)$ vs amount adsorbed $(\mathrm{mg} / \mathrm{g})$ as shown in Figs. 3, 4 and 5, respectively for different values of $\mathrm{pH}$ and temperatures. Sorption isotherm follows Langmuir equation (Eqn. 1) ${ }^{(10)}$ better than Freundlich equation (Eqn. 2) ${ }^{(11)}$.

$$
\begin{aligned}
& C_{\mathrm{e}} /(x / m)=1 / q_{\mathrm{m}} b+C_{\mathrm{e}} / q_{\mathrm{m}} \\
& \log x / m=\log k_{\mathrm{F}}+1 / \mathrm{n} \log C_{\mathrm{e}}
\end{aligned}
$$




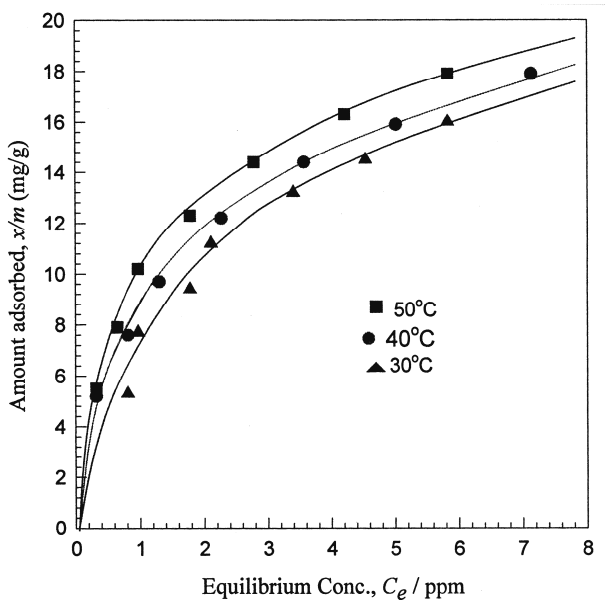

Fig. 3. Adsorption isotherms of lead (II) on UBTLs at different temperatures at $\mathrm{pH}$ 4.0.

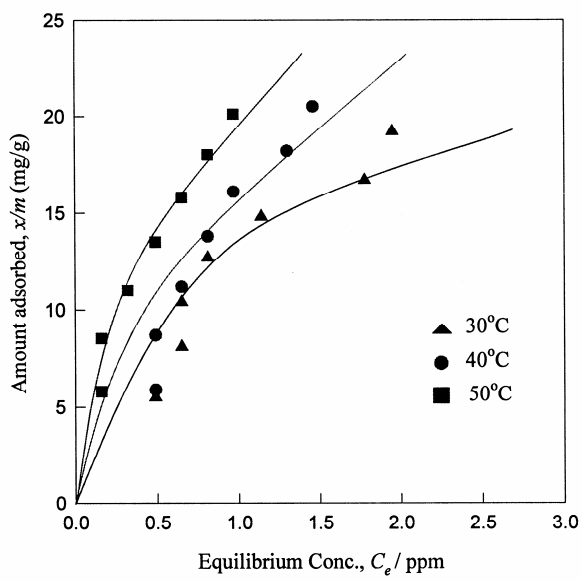

Fig. 4. Adsorption isotherms of lead (II) on UBTLs at different temperatures at pH 5.0

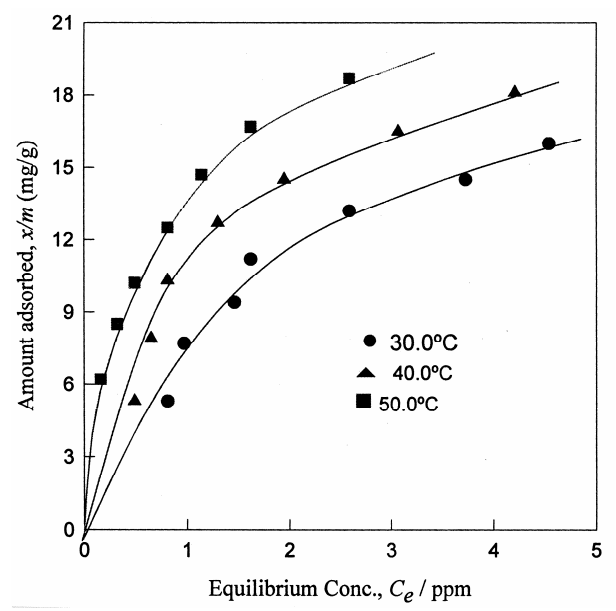

Fig. 5. Adsorption isotherm of lead (II) on UBTLs at different temperatures and at pH 6.0. 
Here, $C_{\mathrm{e}}$ is the equilibrium concentration of $\mathrm{Pb}$ (II) in solution, $x$ is the amount of $\mathrm{Pb}$ (II) sorbed on UBTLs, $m$ is the amount of UBTLs used for sorption and $k_{\mathrm{F}}$ is Freundlich constant. Figs. 6-8 show that Langmuir equation is best fitted for the sorption of $\mathrm{Pb}$ (II) on used tea leaves at higher temperature compared with those of low temperatures in the range of 30-50 ${ }^{\circ} \mathrm{C}$. Langmuir constants at different temperatures and $\mathrm{pH}$ were calculated from Figs. 6-8 and given in Table 1. The maximum mono-layer sorption capacity evaluated from Langmuir constant $\left(q_{\mathrm{m}}\right)$ shows that $\mathrm{pH} 5$ is suitable to obtain maximum mono-layer capacity. Table 1 shows that the maximum mono-layer capacity decreases with increase in sorption temperature at all $\mathrm{pH}$ values but the adsorption intensity constant, $b$ increases with increasing sorption temperature. The adsorption isotherms (Figs. 3-5), and isobars (Fig. 9) show that the total sorption capacity at all $\mathrm{pH}$ values increases with increasing sorption temperature. Such types of observations suggest that the mono-layer sorption and chemical interaction both occurred simultaneously. The mono-layer sorption is due to physical forces. The increase in sorption with temperature suggests that the chemical interaction occurred with increasing temperature resulting the increase of adsorption intensity with temperature.

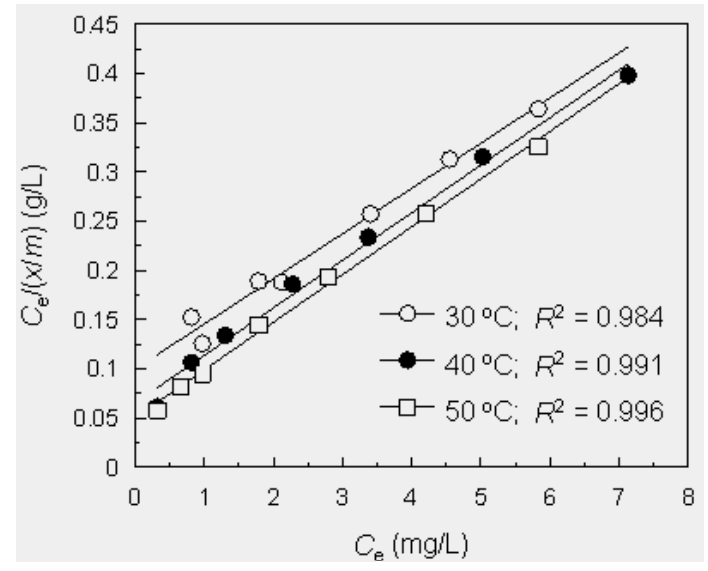

Fig. 6. Langmuir adsorption isotherm of $\mathrm{Pb}(\mathrm{II})$ on UBTLs at different temperatures and at $\mathrm{pH} 4.0$.

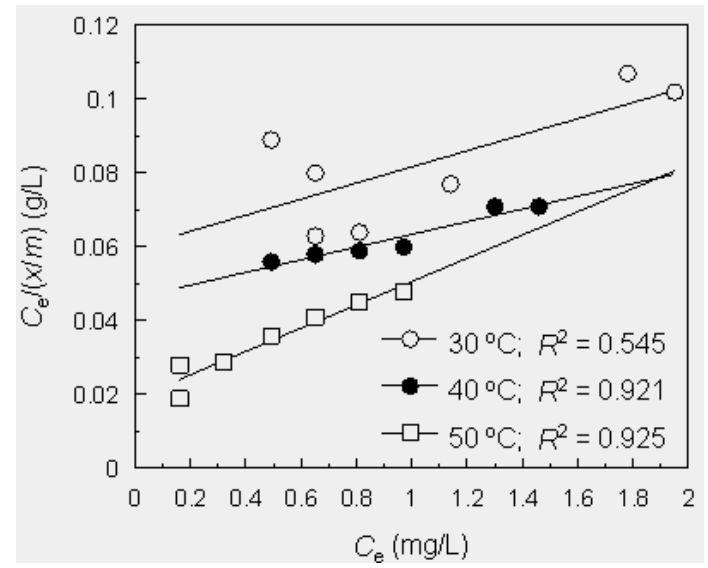

Fig. 7. Langmuir adsorption isotherm of $\mathrm{Pb}(\mathrm{II})$ on UBTLs at different temperatures and at $\mathrm{pH}$ 5.0. 


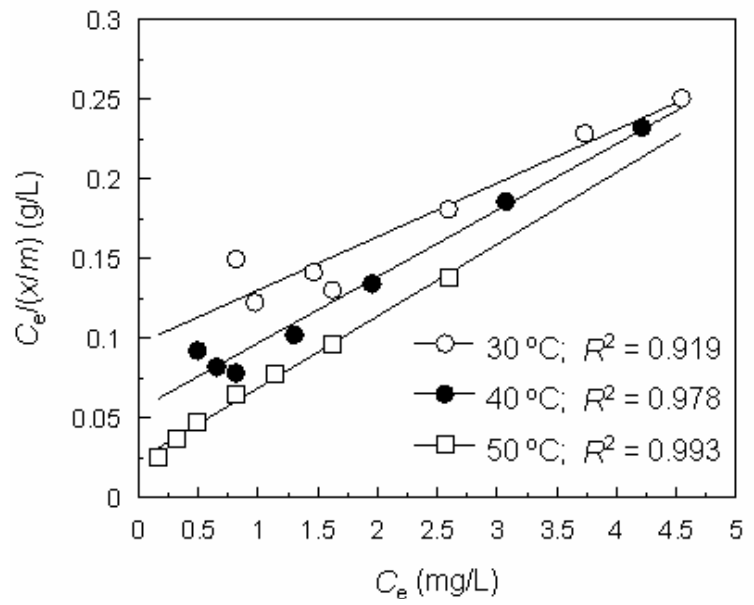

Fig. 8. Langmuir adsorption isotherm of $\mathrm{Pb}(\mathrm{II})$ on UBTLs at different temperatures and at $\mathrm{pH}$ 6.0.

Table 1.

Langmuir parameters for adsorption $\mathrm{OF} \mathrm{Pb}(\mathrm{II})$ on used tea leaves at different temperatures and $\mathrm{PH}$

\begin{tabular}{cccccccccc}
\hline & \multicolumn{3}{c}{$q_{\mathrm{m}}(\mathrm{mg} / \mathrm{L})$} & \multicolumn{3}{c}{$b$} & \multicolumn{3}{c}{$R^{2}$} \\
\cline { 2 - 10 } $\mathrm{pH}$ & \multicolumn{2}{c}{ Temperature $\left({ }^{\circ} \mathrm{C}\right)$} & \multicolumn{3}{c}{ Temperature $\left({ }^{\circ} \mathrm{C}\right)$} & \multicolumn{3}{c}{ Temperature $\left({ }^{\circ} \mathrm{C}\right)$} \\
\cline { 2 - 10 } & 30 & 40 & 50 & 30 & 40 & 50 & 30 & 40 & 50 \\
\hline 4.0 & 21.786 & 20.704 & 20.661 & 0.459 & 0.736 & 0.951 & 0.984 & 0.991 & 0.996 \\
5.0 & 45.872 & 58.140 & 31.746 & 0.364 & 0.372 & 1.649 & 0.545 & 0.921 & 0.925 \\
6.0 & 29.762 & 23.981 & 22.173 & 0.347 & 0.750 & 1.879 & 0.919 & 0.978 & 0.993 \\
\hline
\end{tabular}

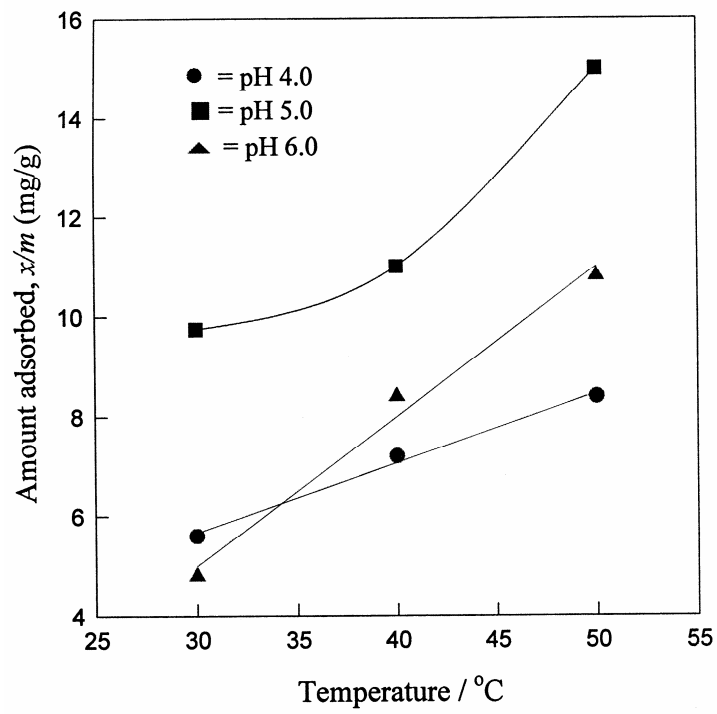

Fig. 9. Adsorption isobars for the adsorption of lead (II) on UBTLs at different $\mathrm{pH}$. 


\section{Adsorption Isobar}

To construct the adsorption isobar, the amount adsorbed at different temperatures under constant equilibrium concentration was estimated from different adsorption isotherms (Figs. 3, 4 and 5). Variation of amount adsorbed with temperature is presented in Fig. 9. Comparison of three isobars at different pHs in Fig. 9 shows that the adsorption increases with the increase of temperature over all $\mathrm{pH}$ values. Significant increase in amount adsorbed was observed at $\mathrm{pH} 5.0$ throughout the range of temperature from 30 to $50{ }^{\circ} \mathrm{C}$. Interestingly, when the $\mathrm{pH}$ of the solution was 4.0 , the increase of adsorption slowed down . The $\mathrm{pH}_{\mathrm{zpc}}$ (zero point charge $\mathrm{pH}$ ) of the surface of tea leaves is very close to $\mathrm{pH} 4.0$ and the surface found almost neutral. At $\mathrm{pH} 5.0$, surface is expected to be negatively charged that helps to adsorb $\mathrm{Pb}^{2+}$ ions. At $\mathrm{pH} 6.0$, surface is more negative than before and sharp increase of adsorption is likely. But experimental results showed that the amount of $\mathrm{Pb}^{2+}$ removal is higher at $\mathrm{pH} 5.0$ than $\mathrm{pH}$ 6.0.

\section{Adsorption Isostere}

To construct adsorption isostere, equilibrium concentrations at different temperatures under constant amount adsorbed ( $\mathrm{mg} / \mathrm{g}$ ) were estimated from the adsorption isotherms (Figs. 3, 4 and 5). Fig. 10 shows a comparison of the variation in equilibrium concentration with temperature as an adsorption isosteric plot. Here the equilibrium concentration decreases with increase in temperature for all $\mathrm{pH}$ values over 4.0 to 6.0.

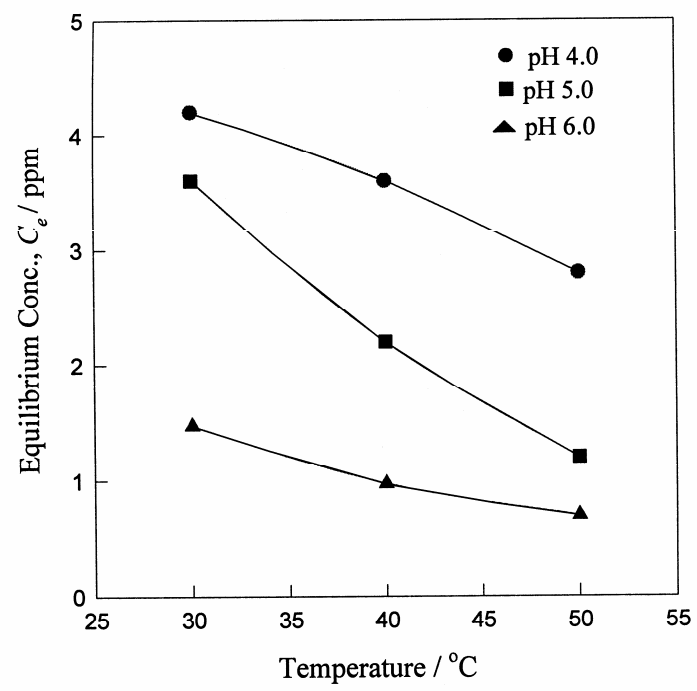

Fig. 10. Adsorption isosteres for the adsorption of lead (II) on UBTLs at different pH.

\section{Sorption Thermodynamics}

Thermodynamic parameters were determined from the findings of the effect of temperature on adsorption and using Equation (3).

$$
\left\{\mathrm{d} \ln C_{\mathrm{e}} / \mathrm{d}(1 / T)\right\}_{\theta=\Delta} H_{\mathrm{ads}} / R
$$


Where, $\theta$ indicates the fraction of surface coverage and $\Delta H_{\mathrm{ads}}$ is the enthalpy of adsorption. For a particular amount adsorbed, the change of equilibrium concentrations with temperature have been calculated from Figs. 3, 4 and 5 for respective pH. Enthalpy of adsorption has been calculated from the slope $\left(\Delta \mathrm{H}_{\text {ads }} / \mathrm{R}\right)$ of the linear plots $\ln C_{\mathrm{e}} \mathrm{vs} 1 / T$ as shown in Fig. 11. The positive values of heat of adsorption vary from 20.22 to 44.71 $\mathrm{kJ} / \mathrm{mol}$. This shows the removal of $\mathrm{Pb}(\mathrm{II})$ ion from aqueous solution of $\mathrm{pH}$ over the range 4.0 to 6.0 is exothermic. Physisorption occur due to weak van der Wall force of attraction between the adsorbate and adsorbent. The adsorbed species lose their kinetic energy which is converted to heat energy. So the physisorption decreases with the increase of temperature.

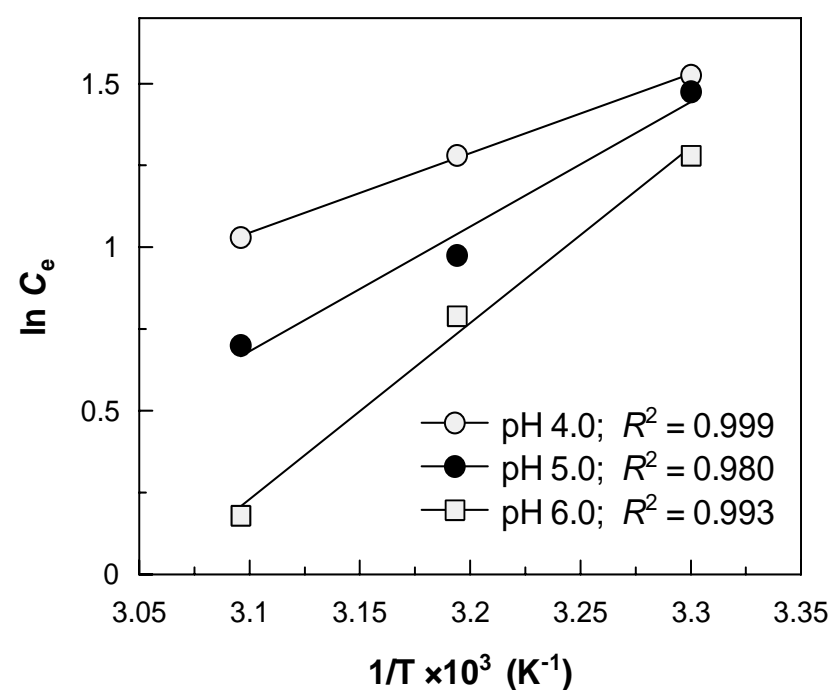

Fig. 11. A plot of $\ln C_{e}$ vs. $1 / T \times 10^{3}$ for the adsorption of $\mathrm{Pb}$ (II) on UBTLs at different $\mathrm{pH}$.

\section{Effect of pH and Sorption Mechanism}

The experimental results in Fig. 12, show that the amount sorbed depends largely on the solution $\mathrm{pH}$. Generally, surface charge of adsorbent and also that of adsorbate are $\mathrm{pH}$ dependent. $\mathrm{Pb}$ (II) exists in acidic medium as free ions but at higher $\mathrm{pH}$ it precipitates as $\mathrm{Pb}(\mathrm{OH})_{2}$. Hence the amount adsorbed and the mechanism of the adsorption is practically controlled by the solution $\mathrm{pH}$.

Figure 12 shows that the amount adsorbed increases with the increase of $\mathrm{pH}$ from 4.0 to 5.0 and after this adsorption decreases with the increase of $\mathrm{pH}$ of the solution. Similar results were obtained during the investigations of removal of $\mathrm{Pb}$ (II) ion from aqueous medium using fresh tea leaves ${ }^{(19)}$ rice husk $^{(15)}$, sago waste ${ }^{(20)}$ and vermiculate ${ }^{(21)}$. 


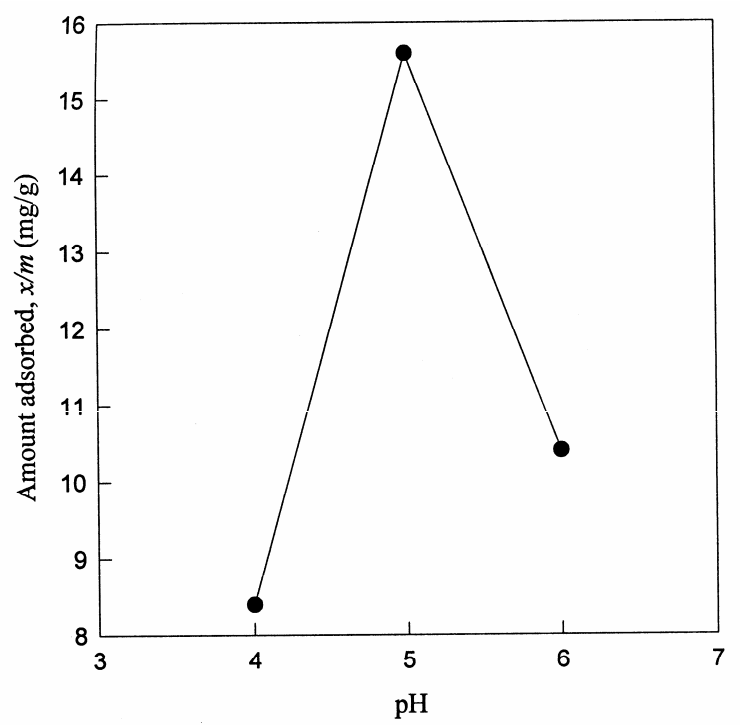

Fig. 12. Variation of amount sorbed with $\mathrm{pH}$ at constant equilibrium concentration at $30.0 \pm 0.5^{\circ} \mathrm{C}$.

At low $\mathrm{pH}$ (4.0), the higher concentration of $\mathrm{H}^{+}$ions is present in the solution, which competes with the metal cation for exchange sites, and as such removal is less at $\mathrm{pH}$ below 4. Above this $\mathrm{pH}$, the concentration of $\mathrm{H}^{+}$ion decreases where the concentration of metal ions remains constant, consequently the removal of metal increases at higher $\mathrm{pH}$ values. The removal of $\mathrm{Pb}(\mathrm{II})$ by ion exchange process at low $\mathrm{pH}$ values had been suggested by Tiemann et al $^{(12)}$ and Das et.al ${ }^{(21)}$.

At $\mathrm{pH}$ 5.0, adsorption increases due to electrostatic force of attraction between negatively charged surface and $\mathrm{Pb}$ (II) ion. The electrostatic force of attraction arises due to the donation of lone pair of electron from oxygen atom of cellulosic material in tea leaves to $\mathrm{Pb}^{2+}$ ion. At higher $\mathrm{pH}$ (higher than 5), adsorption had been observed to decrease again. Similar observation was always found by Eligwe et al ${ }^{(13)}$, and Khalid et $a l^{(15)} . \mathrm{Pb}(\mathrm{II})$ ion undergoes following reaction at $\mathrm{pH} 5.0^{(19)}$.

$$
\begin{aligned}
& \mathrm{Pb}^{2+}+\mathrm{OH}^{-} \rightarrow \mathrm{Pb}(\mathrm{OH})^{+} \\
& \mathrm{Pb}(\mathrm{OH})^{+}+\mathrm{OH}^{-} \rightarrow \mathrm{Pb}(\mathrm{OH})_{2}
\end{aligned}
$$

Eventually $\mathrm{Pb}(\mathrm{OH})^{+}$is also removed by electrostatic force of attraction of negatively charged surface. Reaction (5) suggests that $\mathrm{Pb}$ is also likely to be removed by precipitation reaction. Reaction (4) and (5) explains the significant increase of $\mathrm{Pb}^{2+}$ removal at $\mathrm{pH}$ 5.0. Further increase of $\mathrm{pH}$ of the solution to $\mathrm{pH} 6.0$, causes the rapid reduction of $\mathrm{Pb}^{2+}$ removal. The following reactions may likely occur under this condition $^{(19)}$. 


$$
\begin{aligned}
& \mathrm{Pb}(\mathrm{OH})_{2}+\mathrm{OH}^{-} \rightarrow \mathrm{Pb}(\mathrm{OH})_{3}{ }^{-} \\
& \mathrm{Pb}(\mathrm{OH})_{3}{ }^{-}+\mathrm{OH}^{-} \rightarrow \mathrm{Pb}(\mathrm{OH})_{4}{ }^{2-}
\end{aligned}
$$

The anion thus formed cannot reach the negatively charged surface. This might be the reason of low adsorption at $\mathrm{pH} 6.0$.

\section{CONCLUSIONS}

Used tea leaves act as a low-cost sorbent for the removal of $\mathrm{Pb}$ (II) from aqueous solution. The sorption is highly dependent on solution $\mathrm{pH}$ and temperature. The amount sorbed increases with increase of initial $\mathrm{pH}$ of the solution, and then decreases passing through a maximum. The maximum sorption corresponds to $\mathrm{pH}$ nearly 5.0 . The sorption isotherms follow Langmuir equation better than Freundlich equation. Again the Langmuir equation is more applicable at higher temperatures than low temperature for all $\mathrm{pH}$ values. With the increase in sorption temperature over all $\mathrm{pH}$ values the monolayer adsorption capacity decreases but the adsorption intensity constant $b$ increases. Again, from the adsorption isotherms, it has been noted that the total adsorption capacity increases with increase in sorption temperature over the range of $\mathrm{pH}$ used. Such observations suggest that the mono-layer adsorption is mainly due to physical forces. Chemical interaction occurs when temperature increases resulting the increase of adsorption intensity with temperature. Therefore, the total removal process is designated as sorption. The value of enthalpy of adsorption $\left(\Delta \mathrm{H}_{\mathrm{ads}}\right)$ was estimated to be $20.22,30.40$ and $44.71 \mathrm{~kJ} / \mathrm{mole}$ at $\mathrm{pH} 4.0,5.0$ and 6.0 respectively. The enthalpy of adsorption increases with increase in solution $\mathrm{pH}$ and its positive value suggests the activated adsorption.

\section{ACKNOWLEDGEMENTS}

The authors express their thanks to the Chairman of Chemistry Department, University of Dhaka, Bangladesh, for providing various facilities during the study.

\section{REFERENCES}

1. J. Schwartz, P. J. Landrigan, R. G. Feldman, E. K. Silbergeld, E. L. Baker, I. H. V. LINDERN, J. Pediatrics. 112(1), 12-17, 1988.

2. B. BruneKeEF, The Sci Total Environ. 38, 79-123, 1984.

3. X. Zhan, A. MiyazaKi And Y. NAKAno, J. Chem. Eng. Jan. 34(10), 1204-1210, 2001.

4. F. A. Cotton And G. W. Wilkinson, Advanced Inorganic Chemistry, 5th Edition, pp. 297 298, John Wiley and Sons, 1998.

5. M. M. Benjamin, R. S. Sletten, R. P. Bailey and T. Bennett, Water Res. 30(11), 26092620, 1996.

6. A. KaIDA, Kogyo Yousi, 29, 209-215, 1976.

7. F. C. Richard AND A. C. M. BourG, Water Res. 25(7), 807-816, 1991.

8. K. UosAKI, Japan Kokai, 75(16), 357-359, 1975.

9. M. Fedrico, Proc.-water qual. Technol. conf. 2, 1829-1853, 1996. 
10. V. M. Dronnet, C. M. G. C. Renard, M. A. V. Axelos and J. F. Thibault, Carbohyd. Poly. 34(1-2), 73-82, 1997.

11. M. C. Kun And Josh Kun, Dizhi Diqiu Нuа хие, 4,109-113, 1997.

12. K. J. Tiemann And G. G. Gomez, Haz. Waste Res. 99, 56-59, 1999.

13. C. A. Eligwe, N. B. Okolue, C. O. Nwambu and C. I. A. Nwoko, Chem. Eng. Technol. 22(1), 45-49, 1999.

14. Y. S. Ho AND G. MCKAY, Water Res. 33(2), 578-584, 1999.

15. N. Khalid, S. Ahmad, S. N. Kiani And J. Ahmed, Separ. Sci. Technol. 33(15), 2349-2362, 1998.

16. M. A. Hossain And T. S. A. Islam, Dhaka Univ. J. Sci. 48(1), 7-12, 2000.

17. M. A. Hossain And T. S. A. Islam, J. Bang. Acad. Sci. 22(1), 91-99, 1998.

18. N. A. Siddique, M. Sc. Thesis, Department of Chemistry, Dhaka University, Bangladesh, 1999.

19. R. U. Mithu, M. Sc. Thesis, Department of Chemistry, Dhaka University, Bangladesh, 2000.

20. S. Y. QueK, D. A. J. WASE AND C. F. ForSTER, Water S. A. 24(3), 251-257, 1998.

21. N. C. DAS AND M. BANDYOPADHYAY, J. of the IPHE, India, 2(4), 1-6, 1991. 